\title{
Procurement Regimens to Reduce Ischemia Reperfusion Injury of Vascular Grafts
}

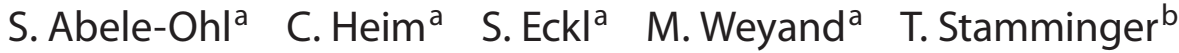 \\ S.M. Ensminger ${ }^{a}$ \\ ${ }^{a}$ Department of Cardiac Surgery and ${ }^{b}$ Institute for Clinical and Molecular Virology, Friedrich-Alexander University \\ Erlangen-Nürnberg, Erlangen, Germany
}

\section{Key Words}

Endothelial cell integrity • Ischemia reperfusion injury •

Tissue culture medium • Transplant arteriosclerosis •

Vascular grafts

\begin{abstract}
Background: Ischemia reperfusion injury is an important nonimmunological factor contributing to the development of chronic rejection. The aim of this study was to compare different cell culture media in terms of vascular lesion formation after ischemia reperfusion injury. Methods: BALB/c aortic grafts were incubated in different cell media (endothelial cell growth, ECG, RPMI-1640 and Waymouth/Ham's F12) for various time spans $(5,6.5$ and $8.5 \mathrm{~h})$ at $37^{\circ} \mathrm{C}$ and implanted into syngeneic $B A L B / c$ recipients. On day 30 after implantation, histology, immunofluorescence and morphometric measurements were performed. Results: A total of 36 transplants were performed for this study with an overall survival rate of $72.2 \%$. The most frequent complication was thrombosis of the aortic graft $(n=9)$ and there was one late death due to other courses. All the recipients with vascular grafts incubated in the ECG medium survived and showed no signs of intimal proliferation independent of the time of ischemia. Aortic grafts incubated in the RPMI medium resulted in a re-
\end{abstract}

duced recipient survival rate of $66.7 \%$ and grafts incubated in the Waymouth medium showed only a $50 \%$ survival by day 30. Analysis of the vascular morphology revealed moderate amounts of intimal proliferation within two aortic grafts in this group. CD31 staining revealed superior endothelial cell integrity after incubation with the ECG medium. Conclusions: Data from the current study suggest that under optimized conditions vascular grafts can be safely kept in tissue culture up to $8.5 \mathrm{~h}$ without significant ischemic damage. Differences in vascular integrity and animal survival depended mostly on the respective tissue culture medium used for the storage of the vessel.

Copyright $\odot 2012$ S. Karger AG, Basel

\section{Introduction}

Cardiac transplantation is the only permanent therapy currently available to return patients with end-stage heart failure to normal life with acceptable 1- and 5-year survival rates ranging between 85 and $75 \%$, respectively [1].

S. Abele-Ohl and C. Heim contributed equally to this work.

\section{KARGER}

Fax +4161306 1234

E-Mail karger@karger.ch

www.karger.com (c) 2012 S. Karger AG, Basel

0014-312X/12/0492-0080\$38.00/0

Accessible online at:

www.karger.com/esr
Stephan M. Ensminger, MD, DPhil, MA

Department of Cardiac Surgery, Friedrich-Alexander University Erlangen-Nürnberg Krankenhausstrasse 12

DE-91054 Erlangen (Germany)

Tel. +49 9131853 3319, E-Mail stephan.ensminger@uk-erlangen.de 
However, the formation of transplant arteriosclerosis, the hallmark feature of chronic rejection, has emerged as a major factor affecting cardiac allograft survival in the long term and is still the leading cause of late mortality after heart transplantation. In contrast to ordinary arteriosclerosis, which usually affects parts of the artery more severely than other parts and produces prominent lesions, transplant arteriosclerosis is characterized by a diffuse, concentric and progressive thickening of the arterial intima that affects minor as well as major coronary arteries of transplanted cardiac allografts $[2,3]$. This results in ischemic damage of the transplanted heart in a sudden or chronic progressive manner with subsequent organ failure.

Transplant arteriosclerosis is a multifactorial process involving immunological factors such as macrophages, $\mathrm{T}$ cells, proinflammatory cytokines, adhesion molecules, growth factors and alloantibodies that have been implicated in both the initiation and progression of this inflammatory process $[3,4]$. In addition, there are nonimmunological factors such as brain death, diseases of the recipient and ischemia/reperfusion injury [5]. The latter is a multifactorial antigen-independent inflammatory reaction resulting in the activation of endothelial cells with increased permeability and expression of various adhesion molecules [6]. These molecules are important for the recruitment and infiltration of effector cells into the postischemic tissue. As a consequence, endothelial cells lose their antiadhesive properties and change to a thrombogenic and adhesive surface. During reperfusion, the ischemia-primed endothelial cells are prone to leukocyte and platelet adhesion, further increasing endothelial cell permeability and cellular activation. Adherent leukocytes release reactive oxygen species and a variety of cytokines, enhancing the inflammatory reaction and enabling leukocytes to transmigrate and enter the subendothelial space [7-10].

Therefore, the role of endothelial cells in allograft rejection is of great interest because they are the first donor cells to come into direct contact with the recipient's blood after ischemia and allow extravasation of leukocytes from the lumen of the vessel through the endothelium, an important barrier into the graft. Endothelial cells can act as antigen-presenting cells and are a major target of the rejection response; they play an important role in the initiation and progression of intima proliferation, a key feature of transplant arteriosclerosis in heart transplant recipients [11]. Consequently, minimization of ischemia reperfusion injury to organ allografts is an important step in improving the long-term survival of heart transplant recipients.

Procurement Regimen and Ischemia

Reperfusion Injury
The aim of this study, therefore, was to investigate whether the use of a defined tissue culture medium for the incubation of vascular grafts during ischemia time has an impact on vascular and endothelial cell integrity. Three different tissue culture media were tested and, prior to implantation into syngeneic recipient mice, vessel segments were incubated for three different time spans $(5,6.5$ and $8.5 \mathrm{~h})$. The Waymouth medium is widely used in organ culture. In combination with Ham's F12 in an equal mixture it seems to be a suitable medium as, among others, Reinhardt et al. [12] used this combination successfully in vitro in a human cytomegalovirus infection of renal arteries. The RPMI medium was formulated to support lymphoblastoid cells in suspension culture and supports a wide variety of cells that are anchorage dependent. Intended to be used with a serum supplement, it supports several cell lines and is widely used in fusion protocols and the growing of hybrid cells. It is regarded as a well-established medium for broader use in cell culture [13]. Finally, the endothelial cell growth (ECG) medium supports the proliferation of endothelial cells and was originally designed as a low serum formulation for the easy detection of cellular metabolites and the enhancement of cellular responses to growth factors [14]. As some of our experimental setups include viral infection steps $[15,16]$, the physiological body temperature of the medium was needed and kept during the time of ischemia. Mouse abdominal aortic transplants were used as an experimental model as they have been shown to represent similar vascular lesions to those observed in human coronary arteries that are affected by transplant arteriosclerosis and, therefore, allow a precise analysis of the composition of the vascular lesions $[17,18]$. Our main readout was recipient survival after transplantation and histological evidence of vascular lesions within explanted vascular grafts. Here we can show that under optimized conditions vascular grafts can be safely kept in tissue culture up to $8.5 \mathrm{~h}$ without significant ischemic damage. Differences in vascular integrity and animal survival depended mostly on the respective tissue culture medium used for the storage of the vessel.

\section{Materials and Methods}

\section{Animals}

$\mathrm{BALB} / \mathrm{c}\left(\mathrm{H} 2^{\mathrm{d}}\right)$ mice were originally purchased from Charles River (Sulzbach, Germany). These mice were used as donors and recipients of the aortic grafts. All mice used in this study were aged between 6 and 12 weeks (weight varied from 19 to $24 \mathrm{~g}$ ) at the time of experimental use and were bred and maintained at the 
animal facility of the Central Animal Facility (Franz-PenzoldtZentrum) at the University of Erlangen-Nürnberg under specific pathogen-free conditions and treated in accordance with institutional and state guidelines.

\section{Tissue Culture Medium}

The following tissue culture media were used: ECG medium (Promocell, Heidelberg, Germany), RPMI 1640 (Gibco, Berlin, Germany) buffered with $25 \mathrm{~mm}$ HEPES and supplemented with glutamine, gentamicin and 15\% fetal calf serum (FCS) and Waymouth's MB 752/1 (Gibco), also supplemented with glutamin, gentamicin and 15\% FCS and mixed in equal parts with Ham's F12 (Gibco). Heparin was added to each medium at a dose of 5,000 IU (Heparin-Natrium-25000; Ratiopharm, Ulm, Germany) in 10 $\mathrm{ml}$ final volume. For incubation, cryotubes $\left(\right.$ Cryovial ${ }^{\circledR}$; Roth, Karlsruhe, Germany) were used and filled with $1.5 \mathrm{ml}$ of the heparinized respective medium. After harvesting, the grafts were incubated at $37^{\circ} \mathrm{C}$ and $5 \% \mathrm{CO}_{2}$. To ensure gas exchange the cryotubes were not completely sealed during incubation.

\section{Abdominal Aortic Transplantation}

The procedure was performed using a modified technique initially described by Koulack et al. [16]. In brief, the donor thoracic aorta was isolated, resected and, after incubation of the graft at a certain time, transferred to the recipient animal. The recipient aorta was clamped and then transected with a sharp microvascular scissors. A proximal end-to-end anastomosis was performed with 8-13 (average 10) single interrupted sutures. The aortic graft was then repositioned and the distal anastomosis continued analogously using 11-0 black nylon monofilament nonadsorbable sutures with a micro-point 3-mm (3/8) needle.

\section{Morphometric Analysis of the Aortic Graft}

Aortic grafts were removed under anesthesia on day 30 after transplantation. Grafts were perfused with saline and were flash frozen in OCT medium (Tissue-Tek ${ }^{\circledR}$, Sakura, Alphen aan den Rijn, The Netherlands) in liquid nitrogen for morphometric analysis of $5-\mu \mathrm{m}$ cryostat sections. Five cross sections from each graft harvested on day 30 were stained with elastin/van Gieson and analyzed by two independent examiners blinded to the experimental conditions using a conventional light microscope (original magnification $\times 200$ ). A digitized image of each section was captured and the areas within the lumen and the internal and external elastic lamina were circumscribed manually and measured as previously described [18]. All image analysis was carried out using ANAlysisi Image Analysis software (Olympus, Hamburg, Germany).

\section{Immunofluorescence}

The process was performed as previously described [15]. In brief, $7-\mu \mathrm{m}$ cryostat sections on gelatin-coated slides were airdried overnight and then fixed in acetone for $10 \mathrm{~min}$. The slides were then rehydrated and preincubated in staining buffer $(0.1 \mathrm{M}$ Tris, $\mathrm{pH} 8.0$ and $0.1 \%$ Tween $20 \%$ ) containing 5\% heat-inactivated mouse serum (Invitrogen, San Diego, Calif., USA) for $15 \mathrm{~min}$. Afterwards, the sections were incubated with purified primary antibodies in a humidified chamber for $1 \mathrm{~h}$. After three washes with staining buffer, detection of antigen was revealed with secondary antibody mouse-anti-rat-IgG-Cy3 (1:100). Unspecific Fc receptors were blocked with staining buffer containing $5 \%$ heat-inacti- vated rat serum (Invitrogen) for $15 \mathrm{~min}$ followed by incubating the slides with CD31-FITC for $1 \mathrm{~h}$. After three final washes the slides were mounted using Vectashield HardSet Mounting medium and analyzed by epifluorescence microscopy (Olympus). Endothelial cells were detected with CD31-FITC (BD Biosciences, Heidelberg, Germany).

\section{Statistical Analysis}

Results are given as the mean per group $\pm \mathrm{SD}$, which was derived from the mean per graft. Statistical differences between two groups were analyzed using the Fisher exact test or a two-tailed Student $t$ test. A p value $<0.05$ was considered significant.

\section{Ethics Statement}

This study was carried out in strict accordance with international guidelines for animal care and use and in accordance with the guidelines of the Animal Care and Use Committee of the Government of Bavaria and the institutional guidelines of the University of Erlangen-Nuremberg. The protocol was approved by the Government of Bavaria (Regierung von Mittelfranken, permit No. 621.2531.31-21/05).

\section{Results}

\section{Survival Rates after Transplantation Differed}

Depending on the Tissue Culture Medium Used

In order to evaluate the most suitable medium for vascular and endothelial cell protection, a total of 36 syngeneic BALB/c abdominal aortic transplantations were performed for this study. The overall survival rate was $72.2 \%$. The most frequent complication was thrombosis of the aortic graft $(n=9)$ and there was one late death of a recipient due to other courses (wasting syndrome leading to euthanasia on the 12 th postoperative day). All the recipients that had received vascular grafts incubated in the ECG medium survived independently of the time of ischemia ( $n=12$; fig. 1,2 ). Aortic grafts incubated in the RPMI medium resulted in a significantly reduced survival rate of $66.7 \%$ for the respective recipients $(n=12$; $\mathrm{p}<0.05$; fig. 2), whereas vascular grafts incubated in the Waymouth medium resulted in only $50 \%$ survival of the transplant recipients ( $\mathrm{n}=12 ; \mathrm{p}<0.01$; fig. 2 ). Compared to incubation with the ECG medium $(n=12)$ only 8 mice survived the procedure after incubation with the RPMI medium ( $\mathrm{n}=12 ; \mathrm{p}<0.05$ vs. ECG medium) and only 6 animals survived the use of the Waymouth medium $(\mathrm{n}=$ 12 ; $\mathrm{p}<0.01$ vs. ECG medium; fig. 2).

\section{Incubation with the Waymouth Medium Resulted in \\ Vascular Lesions of the Explanted Grafts}

$\mathrm{BALB} / \mathrm{c}$ aortic isografts from $\mathrm{BALB} / \mathrm{c}$ recipients were analyzed 30 days after transplantation, the time point at 

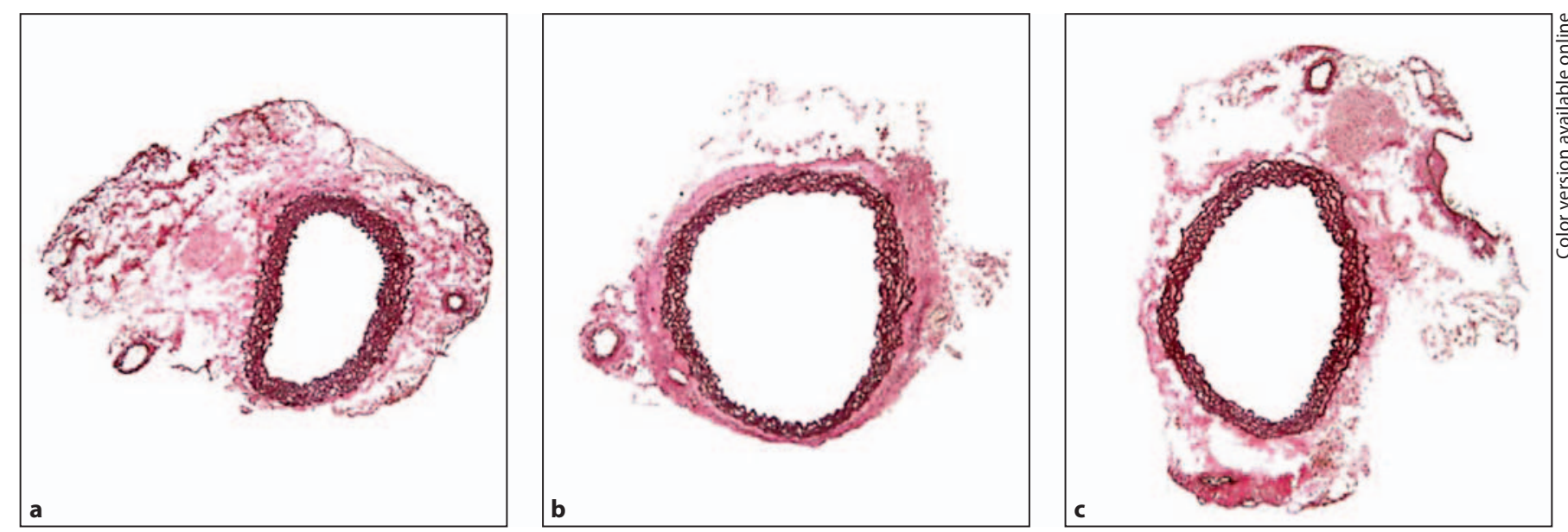

Fig. 1. Histopathological evaluation of the morphology of syngeneic Balb/C aortic grafts implanted into Balb/C recipients showed no intimal proliferation 30 days after transplantation after graft incubation in ECG medium for three different time spans: $5 \mathrm{~h}$ (a),

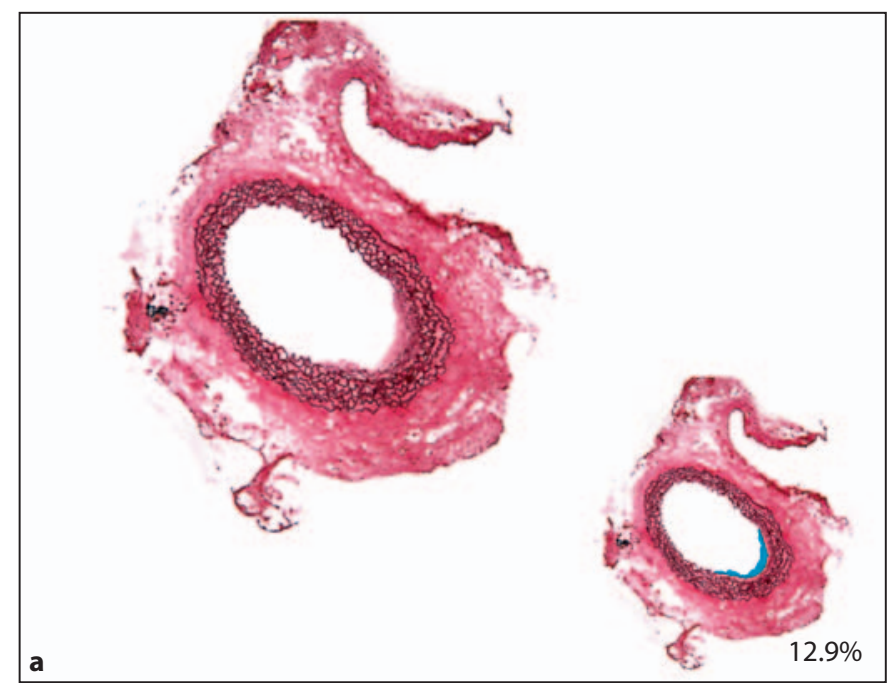

Fig. 2. Using the Waymouth/Ham F12 medium (a) for incubating the graft for about $6.5 \mathrm{~h}$ showed significant amounts of intimal proliferation 30 days after the transplantation of syngeneic $\mathrm{BALB} / \mathrm{c}$ aortic grafts. For morphometric analysis of the degree of intimal thickening, sections were stained with Miller's elastin/ van Gieson stain. Original magnification $\times 100$. The area within the lumen and the internal and external elastic lamina were cir-

which distinctive changes of transplant arteriosclerosis are most evident [20]. All the recipients that had received grafts incubated in the ECG or RPMI media showed no signs of intimal proliferation independently of the time span of ischemia (fig. 1,2). Analysis of vas-
$6.5 \mathrm{~h} \mathrm{(b)}$ and $8.5 \mathrm{~h}(\mathbf{c})$. The tissue was snap-frozen and sections were stained with Miller's elastin/van Gieson stain. Original magnification $\times 100$.

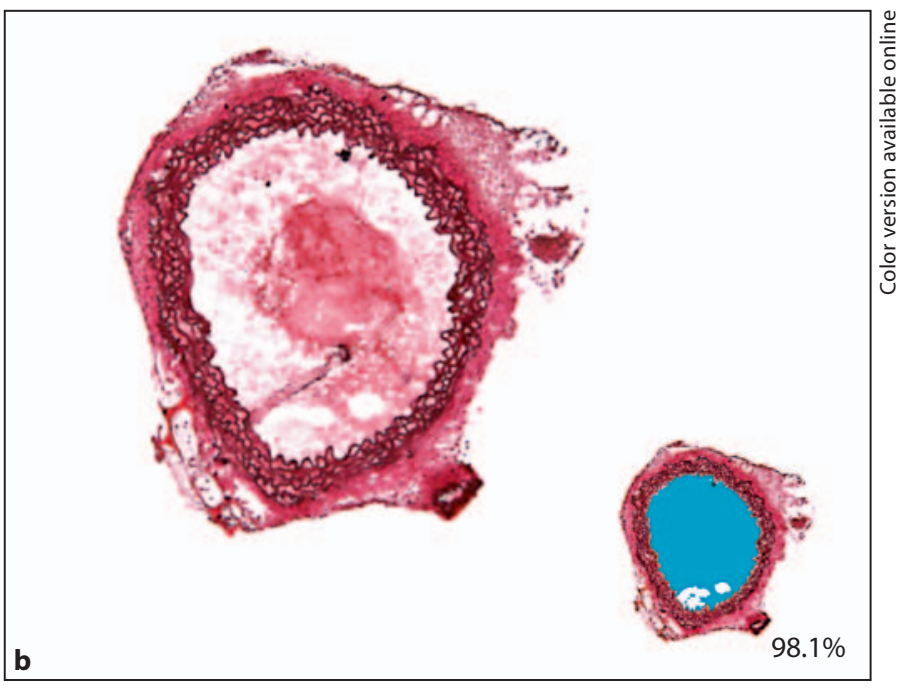

cumscribed manually and measured. From the measurement a quotient for the thickness of the intima $\left(Q_{\text {int }}\right)$ was calculated. $Q_{\text {int }}$ indicates the relative thickness (\%) of the intima. After using the Waymouth medium for incubation of the isografts a large obstructive thrombus was seen in the vascular lumen of a euthanized mouse (b) on day 2 after transplantation because of paralyzed hind limbs. Waymouth medium revealed moderate amounts of intimal proliferation (18.7 $\pm 8.3 \%$; fig. $3 a)$. In addition, after isograft incubation of $5 \mathrm{~h}, 4$ recipients in the Waymouth group died because of paralyses in the hind limbs 
and histology revealed thrombosis of the graft (fig. 3b). In contrast, there was excellent morphology and recipient survival after incubation of the vessels with the ECG medium (fig. 1).

\section{Good Vascular Endothelial Integrity after Prior}

Incubation with the ECG and RPMI Media

Within the aortic allografts recovered on day 30 after transplantation, immunofluorescence analysis revealed a significant decrease in endothelial CD31 staining of the vascular isograft after incubation for $8.5 \mathrm{~h}$ with the Waymouth medium (fig. 4). In contrast, explanted aortic isografts after incubation ( $8.5 \mathrm{~h}$ ) with the ECG and RPMI media showed good CD31 integrity, whereas the endothelium in the group using the Waymouth medium appeared defective (fig. 4). The quantification of the CD31 positive cells with computerized image analysis confirmed a significant decline of the endothelial barrier in the Waymouth group ( $\mathrm{n}=12$ animals per group; $\mathrm{p}<0.05$ vs. native aorta; fig. 4).

\section{Discussion}

Allograft rejection results in multiple proinflammatory insults to the graft, most of which are associated with endothelial cell activation and leukocyte infiltration into the graft. Graft endothelium can, therefore, influence allograft rejection in many ways, e.g. by interacting with $\mathrm{T}$ cells, which are critical for inflammatory cell recruitment into the parenchyma of allografts and may also participate in the activation of alloreactive $T$ lymphocytes via the presentation of alloantigen and effective costimulatory signals $[21,22]$. Therefore, procurement regimens for endothelial cell protection are of crucial clinical importance for all aspects of surgery (e.g. harvesting veins for bypass surgery or complex microsurgical reconstructions such as flap reconstruction or replantation) and organ transplantation as in this setting endothelial cells are the first cells that come into contact with the recipient's blood after a period of cold ischemia.

It was the aim of the current study to investigate the potential of three different tissue culture media to protect endothelial cell integrity during variable times of warm ischemia in an experimental mouse aortic transplant model, in particular exploring the time window for therapeutic interventions. Here we can demonstrate that under optimized conditions vascular grafts can be kept safely in tissue culture up to $8.5 \mathrm{~h}$ without significant ischemic damage. Differences in vascular integrity and

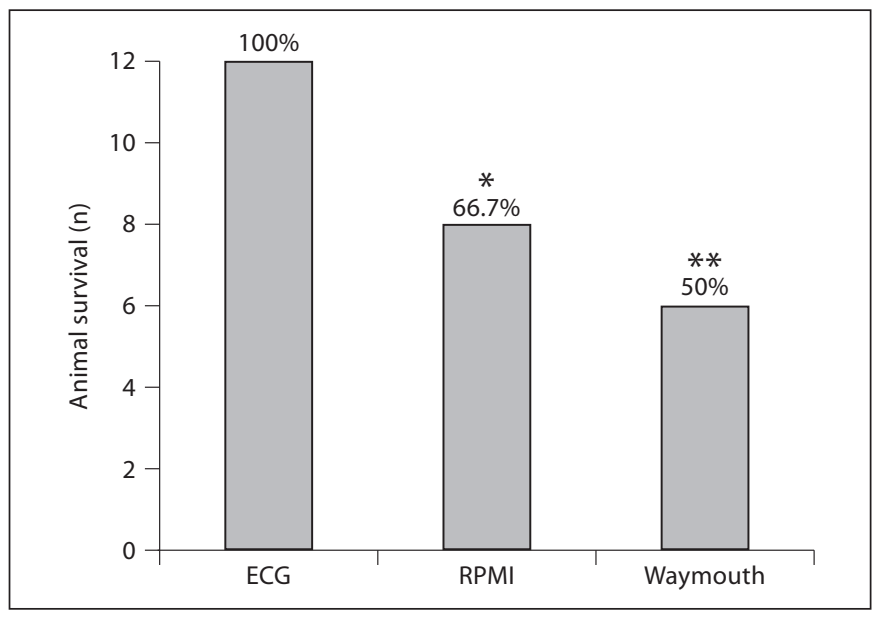

Fig. 3. Quantification of recipient survival after isograft implantation using three different tissue culture media for incubation of the vascular grafts until surgery. Using different media (ECG, RPMI and Waymouth) resulted in a significant higher rate of mortality after incubation with the RPMI and Waymouth media compared to no mortality after incubation of the vascular grafts in the ECG medium ( $\mathrm{n}=12$ animals/group; $\mathrm{n}=4$ animals/time point). ${ }^{*} \mathrm{p}<$ 0.05 versus ECG medium; ${ }^{* *} \mathrm{p}<0.01$ versus ECG medium.

animal survival depended mostly on the respective tissue culture medium used for the storage of the vessel. Only syngeneic grafts incubated in the Waymouth medium revealed intimal proliferation of smooth muscle cells within the recovered syngeneic aortic grafts, a feature that is usually seen after allogeneic transplantation, and demonstrated an overall reduced survival of $50 \%$. In addition, CD31 staining revealed superior endothelial cell integrity after incubation with the ECG medium compared to incubation with the RPMI and Waymouth media.

In order to investigate the impact of ischemia and reperfusion injury as isolated risk factors for the development of transplant arteriosclerosis, it was decided to perform syngeneic abdominal aortic transplants to eliminate an alloimmune response. As reported by our group and several others $[15,23,24]$, syngeneic grafts do not develop any vascular disease up to $2 \mathrm{~h}$ after ischemia and subsequent transplantation and display an intact intimal layer upon histological analysis [15, 17, 23-27]. The respective ischemia times were determined with regard to experimental requirements and relevant clinical situations, e.g. recovered arteries awaiting bypass surgery and explanted organs waiting for transplantation. Furthermore, prolonged ischemia time without adequate procurement and protection can lead to the activation of endothelial cells, leukocytes and platelets by the release of 

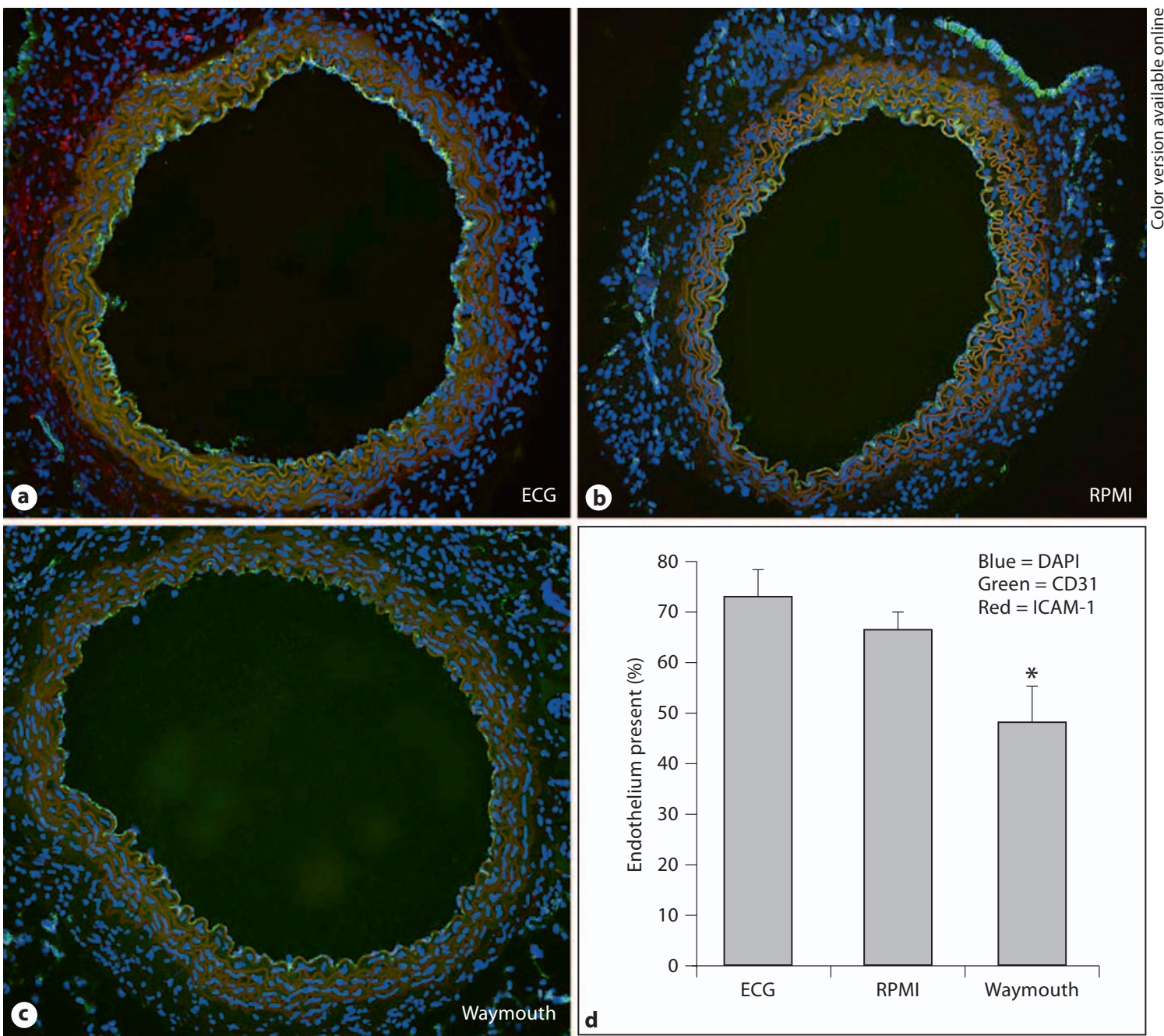

Fig. 4. Immunofluorescence of cryostat sections from aortic allografts 30 days after transplantation using the three different media, ECG (a), RPMI (b) and Waymouth (c) for an incubation time of $8.5 \mathrm{~h}$. d Quantification of mean endothelial CD31 staining on day 30 after transplantation was performed with computerized image analysis. The positive-stained area in relation to the intact endothelium of native aortas of each section was analyzed. Original magnification $\times 200 . \mathrm{n}=12$ animals/group; $\mathrm{n}=4$ animals/time point. ${ }^{*} \mathrm{p}<0.05$ versus native aorta.

cytokines and the upregulation of adhesion molecules $[23,24,28]$.

Interestingly, we found no significant difference between the survival rates of the mice implanted with grafts exposed to the shortest ischemia time and grafts exposed to the longest ischemia time within the respective experimental groups. All the recipients that had received a graft incubated in the ECG medium survived independent of the time of ischemia, whereas $50 \%$ of the recipients died in the Waymouth medium group at various time points after implantation. Therefore, our data sug- gest that in our experimental setting the respective tissue culture medium used for the storage of the vascular transplant may be responsible for the observed differences in survival and not necessarily the respective time of ischemia.

All the tissue culture media used in this study were supplemented with FCS. This is thought to have a beneficial effect on the integrity of endothelial cells, as it contains numerous proteins, growth factors and various other substrates [29]. Interestingly, in the present study, incubation with the ECG medium [30] resulted in superior 
endothelial protection and recipient survival and this medium contains only $2 \%$ FCS, whereas the RPMI and Waymouth media are supplemented with 15\% FCS. Therefore, we would speculate at this stage that higher concentrations of FCS do not necessarily have a beneficial effect on endothelial integrity. In contrast to the Waymouth and RPMI media, the ECG medium contains bovine hypothalamus, endothelial growth factor, basic fibroblast growth factor (bFGF) and hydrocortisone. Therefore, the combination of growth factors such as epidermal growth factor and the basic fibroblast factor and hormones, in combination with a low serum growth medium within the ECG medium, seems very suitable for the proliferation and protection of endothelial cells. In addition, hydrocortisone is well known to reduce neutrophils and their adherence to endothelial cells, thereby preventing the migration of neutrophils into the graft and the vascular wall, possibly by decreasing vascular inflammation.

Each medium was supplemented with heparin as described in Materials and Methods (5,000 IU heparin/10 $\mathrm{ml}$ of each medium) to minimize thrombosis of the vascular grafts. The combination of bFGF and heparin may even improve the protection of the vascular grafts because of heparin's ability of cell-free binding bFGF to soluble receptors [31]. bFGF is naturally located in the nucleus of endothelial cells and SMCs within the arterial wall and is released upon cell injury, acting as mitogen to surrounding cells [32]. Although bFGF is considered to increase neointimal SMC proliferation in injured arteries $[33,34]$, some data clearly showed that the coadministration of heparin suppressed intimal hyperplasia and SMC proliferation $[35,36]$.

Obviously endothelial integrity is a crucial point for procurement regimen. In the current study, endothelial integrity was confirmed by staining for CD31 (PECAM-1).
This single-chain type-1 transmembrane protein belongs to the immunoglobulin superfamily and is expressed on continuous endothelium [37], its expression on endothelial cells indicating their morphological integrity [34]. Data of the current study reveal good endothelial integrity within grafts incubated in the ECG and RPMI media, whereas incubation with the Waymouth medium appeared not to have such a protective effect on endothelial cells. Vascular grafts from this group showed numerous gaps and defects within the endothelial layer and a significantly reduced CD31 expression. In our view, this may also be the reason for the intimal proliferation seen in this group. In addition, endothelial gaps are able to trigger thrombus formation within the vascular graft and may also be an explanation for the reduced survival of recipients within this group.

In conclusion, we could show that under optimized conditions vascular grafts can be safely kept in tissue culture up to $8.5 \mathrm{~h}$ without significant ischemic damage. Differences in vascular integrity and animal survival depended mostly on the respective tissue culture medium used for the storage of the vascular graft. In this regard, the ECG medium was the most suitable procurement regimen, ensuring a well-preserved endothelium within the transplanted vascular grafts.

\section{Acknowledgements}

The authors would like to thank Professor von Hoersten and the staff of the animal facility of the University of ErlangenNuremberg for their expert care of the animals used for this study. We would also like to thank Dr. Tim Worbs of the Hannover Medical School for the supply of his macro for analyzing our immunofluorescence by ImageJ. This work was supported by grants from the ELAN funds and the IZKF of the University of ErlangenNürnberg and the ADUMED Foundation.

\section{References}

1 Stehlik J, Edwards LB, Kucheryavaya AY, Aurora P, Christie JD, Kirk R, Dobbels F, Rahmel AO, Hertz MI: The Registry of the International Society for Heart and Lung Transplantation: twenty-seventh official adult heart transplant report - 2010. J Heart Lung Transplant 2010;29:1089-1103.

2 Weis M, von Scheidt W: Coronary artery disease in the transplanted heart. Annu Rev Med 2000;51:81-100.
3 Lietz K, Miller LW: Current understanding and management of allograft vasculopathy. Semin Thorac Cardiovasc Surg 2004;16: 386-394.

4 Libby P: What have we learned about the biology of atherosclerosis? The role of inflammation. Am J Cardiol 2001;88:3J-6J.

5 Pratschke J, Weiss S, Neuhaus P, Pascher A: Review of nonimmunological causes for deteriorated graft function and graft loss after transplantation. Transpl Int 2008;21:512522.
6 Burne-Taney MJ, Rabb H: The role of adhesion molecules and $\mathrm{T}$ cells in ischemic renal injury. Curr Opin Nephrol Hypertens 2003; 12:85-90.

7 Rabb H: The T cell as a bridge between innate and adaptive immune systems: implications for the kidney. Kidney Int 2002;61:19351946

8 Boros P, Bromberg JS: New cellular and molecular immune pathways in ischemia/reperfusion injury. Am J Transplant 2006;6: 652-658. 
9 Kupiec-Weglinski JW, Busuttil RW: Ischemia and reperfusion injury in liver transplantation. Transplant Proc 2005;37:16531656.

10 Ysebaert DK, De Greef KE, De Beuf A, Van Rompay AR, Vercauteren S, Persy VP, De Broe ME: T cells as mediators in renal ischemia/reperfusion injury. Kidney Int 2004; 66:491-496.

11 Ensminger SM, Spriewald BM, Steger U, Morris PJ, Mak TW, Wood KJ: Platelet-endothelial cell adhesion molecule-1 (CD31) expression on donor endothelial cells attenuates the development of transplant arteriosclerosis. Transplantation 2002;74:12671273.

12 Reinhardt B, Vaida B, Voisard R, Keller L, Breul J, Metzger H, Herter T, Baur R, Luske A, Mertens T: Human cytomegalovirus infection in human renal arteries in vitro. J Virol Methods 2003;109:1-9.

13 Lindl T, Gstraunthaler G: Zell- und Gewebekultur. Von den Grundlagen zur Laborbank. Heidelberg, Spektrum Akademischer Verlag, 2008.

14 Cohen J, Wilkin GP: Neural Cell Culture: A Practical Approach. Oxford, IRL Press at Oxford University Press, 1995.

15 Heim C, Abele-Ohl S, Eckl S, RamspergerGleixner M, Mahmoudian S, Weyand M, Stamminger T, Ensminger SM: Murine cytomegalovirus infection leads to increased levels of transplant arteriosclerosis in a murine aortic allograft model. Transplantation 2010;90:373-379.

16 Abele-Ohl S, Leis M, Wollin M et al: Human cytomegalovirus infection leads to elevated levels of transplant arteriosclerosis in a humanized mouse aortic xenograft model. Am J Transplant 2012; 12:1720-1729.

17 Koulack J, McAlister VC, Giacomantonio CA, Bitter-Suermann H, MacDonald AS, Lee TD: Development of a mouse aortic transplant model of chronic rejection. Microsurgery 1995;16:110-113.

18 Ensminger SM, Billing JS, Morris PJ, Wood $\mathrm{KJ}$ : Development of a combined cardiac and aortic transplant model to investigate the development of transplant arteriosclerosis in the mouse. J Heart Lung Transplant 2000;19: 1039-1046.
19 Ensminger SM, Witzke O, Spriewald BM, Morrison K, Morris PJ, Rose ML, Wood KJ: $\mathrm{CD} 8+\mathrm{T}$ cells contribute to the development of transplant arteriosclerosis despite CD154 blockade. Transplantation 2000;69:26092612.

20 Ensminger SM, Spriewald BM, Witzke O, Morrison K, Pajaro OE, Morris PJ, Rose ML, Wood KJ: Kinetics of transplant arteriosclerosis in MHC-class I mismatched and fully allogeneic mouse aortic allografts. Transplantation 2002;73:1068-1074.

21 Pober JS, Orosz CG, Rose ML, Savage CO: Can graft endothelial cells initiate a host anti-graft immune response? Transplantation 1996;61:343-349.

22 Briscoe DM, Alexander SI, Lichtman $\mathrm{AH}$ Interactions between $\mathrm{T}$ lymphocytes and endothelial cells in allograft rejection. Curr Opin Immunol 1998;10:525-531.

23 Abele S, Spriewald BM, Ramsperger-Gleixner M, Wollin M, Hiemann NE, Nieswandt B, Weyand M, Ensminger SM: Attenuation of transplant arteriosclerosis with clopidogrel is associated with a reduction of infiltrating dendritic cells and macrophages in murine aortic allografts. Transplantation 2009;87:207-216.

24 Eckl S, Heim C, Abele-Ohl S, Hoffmann J, Ramsperger-Gleixner $M$, Weyand $M$, and Ensminger SM: Combination of clopidogrel and everolimus dramatically reduced the development of transplant arteriosclerosis in murine aortic allografts. Transpl Int 2010; 23:959-966.

25 Ensminger SM, Spriewald BM, Fischlein T, Weyand M, Morris PJ, Wood KJ: Mouse endothelial CD40 expression does not play a role during the development of transplant arteriosclerosis. Endothelium 2003;10:111117.

26 Sun H, Subbotin V, Woodward J, Valdivia L, Fung JJ, Rao AS: Role of MHC class I and CD8(+) T cells in the pathogenesis of chronic rejection. Transplant Proc 2001;33:319.
27 Raisanen-Sokolowski A, Glysing-Jensen T, Koglin J, Russell ME: Reduced transplant arteriosclerosis in murine cardiac allografts placed in interferon-gamma knockout recipients. Am J Pathol 1998;152:359-365.

28 Heim C, Eckl S, Gebhardt J, Weyand M, Ensminger SM: The underestimated role of platelets in heart transplantation. Z HerzThorax- Gefässchir 2010;24:241-250.

29 Feng XJ, Van Hove CE, Walter PJ, Herman AG: Effects of storage temperature and fetal calf serum on the endothelium of porcine aortic valves. J Thorac Cardiovasc Surg 1996; 111:218-230.

30 Lambert KJ, Birch JR: Cell growth media. Anim Cell Biotechnol 1985;1:85-122.

31 Ornitz DM, Yayon A, Flanagan JG, Svahn CM, Levi E, Leder P: Heparin is required for cell-free binding of basic fibroblast growth factor to a soluble receptor and for mitogenesis in whole cells. Mol Cell Biol 1992;12: 240-247.

32 Lindner V, Reidy MA: Proliferation of smooth muscle cells after vascular injury is inhibited by an antibody against basic fibroblast growth factor. Proc Natl Acad Sci USA 1991;88:3739-3743.

33 Wolf SC, Sauter G, Rodemann HP, Risler T, Brehm BR: Influence of growth factors on the proliferation of vascular smooth muscle cells isolated from subtotally nephrectomized rats after endothelin or angiotensin II antagonism. Nephrol Dial Transplant 2005; 20:312-318.

34 Lindner V, Lappi DA, Baird A, Majack RA, Reidy MA: Role of basic fibroblast growth factor in vascular lesion formation. Circ Res 1991;68:106-113.

35 Edelman ER, Adams DH, Karnovsky MJ: Effect of controlled adventitial heparin delivery on smooth muscle cell proliferation following endothelial injury. Proc Natl Acad Sci USA 1990;87:3773-3777.

36 Edelman ER, Nugent MA, Smith LT, Karnovsky MJ: Basic fibroblast growth factor enhances the coupling of intimal hyperplasia and proliferation of vasa vasorum in injured rat arteries. J Clin Invest 1992;89:465473.

37 Woodfin A, Voisin MB, Nourshargh S: PECAM-1: a multi-functional molecule in inflammation and vascular biology. Arterioscler Thromb Vasc Biol 2007;27:2514-2523. 